\title{
openheart Engaging older patients in cardiovascular research: observational analysis of the ICON-1 study
}

\author{
Hannah Sinclair, ${ }^{1,2}$ Jonathan A Batty, ${ }^{1,2}$ Weiliang Qiu, ${ }^{3}$ Vijay Kunadian ${ }^{1,2}$
}

To cite: Sinclair H, Batty JA, Qiu W, et al. Engaging older patients in cardiovascular research: observational analysis of the ICON-1 study. Open Heart 2016;3:e000436. doi:10.1136/openhrt-2016000436

Received 14 March 2016 Revised 5 May 2016 Accepted 30 June 2016

\section{CrossMark}

\footnotetext{
${ }^{1}$ Faculty of Medical Sciences Institute of Cellular Medicine, Newcastle University, Newcastle upon Tyne, UK ${ }^{2}$ Cardiothoracic Centre, Freeman Hospital, Newcastle upon Tyne Hospitals NHS Foundation Trust, Newcastle upon Tyne, UK

${ }^{3}$ Channing Division of Network Medicine, Brigham and Women's Hospital and Harvard Medical School, Boston, Massachusetts, USA

Correspondence to Dr Vijay Kunadian; vijay. kunadian@newcastle.ac.uk
}

\section{ABSTRACT}

Background: As a consequence of population ageing, the number of older patients presenting with acute coronary syndrome (ACS) is increasing. The historical underrepresentation of older patients in many pivotal ACS clinical trials undermines the practice of evidencebased medicine in this high-risk cohort. This study evaluates the feasibility of recruitment of older patients to a longitudinal, clinical study.

Methods: The study to Improve Cardiovascular Outcomes in high-risk patieNts with ACS (ICON-1) is an observational, prospective cohort study investigating predictors of poor outcome in older patients with ACS. All patients aged $\geq 75$ years, referred to a tertiary cardiovascular centre in the North East of England for coronary angiography with a view to urgent percutaneous coronary intervention, were screened for inclusion. A screening log was prospectively maintained, and a detailed analysis was performed to identify the factors associated with recruitment and non-recruitment to ICON-1.

Results: Of the 629 patients screened over 34 months, $457(72.7 \%)$ satisfied the a priori-defined study inclusion/exclusion criteria. Of those eligible to participate, 300 (68.5\%) provided informed consent and were recruited to the study; 59 (13.5\%) were unable to consent due to a lack of capacity or limitations in communication, and 79 patients (18.0\%) declined to participate in the study. Those lacking adequate capacity to consent were older than those able to provide informed consent $(83.0 \pm 4.7$ vs 81.0 \pm 4.7 years, $p=0.002$ ). Women were more likely to decline than men $(25.1 \%$ vs $10.0 \%, p<0.001)$.

Conclusions: The recruitment of patients was robust, comparing favourably to previous longitudinal studies within this age group. Although enrolling older people to research remains challenging, this cohort is enthusiastic to participate. The contribution of older patients must not be ignored, particularly in the setting of an ever-ageing population, in whom cardiovascular disease burden is high.

Trial registration number: NCT01933581; Pre-results.

\section{INTRODUCTION}

Our population is ageing. In England and Wales, the number of people aged 65 years or over increased by 1.7 million, from 1985

\section{KEY QUESTIONS}

What is already known about this subject?

- As a consequence of population ageing, the number of older patients presenting with acute coronary syndrome (ACS) is increasing. Despite the availability of pharmacological and invasive management options, the landmark studies that demonstrated the safety and efficacy of these approaches routinely underrepresented and excluded older patients, undermining the practice of evidence-based medicine in this high-risk cohort. The recruitment of older patients in clinical research is traditionally considered problematic; challenges include (1) increased frequency of cognitive and sensory impairment, precluding informed consent, (2) high prevalence of baseline comorbidity and polypharmacy and (3) multifactorial loss to follow-up.

What does this study add?

- The present study illustrates the feasibility of including older patients in observational clinical research in the setting of ACS. The majority of patients satisfying the study eligibility criteria were successfully recruited; a minority of patients lacked capacity to provide informed consent, and few declined to participate in the study. Women had a greater tendency to decline to participate as compared with men, which is reflected in the lower number of women recruited to the study overall. The present experience demonstrates that older patients are generally amenable to consenting to participate in clinical research.

How might this impact on clinical practice?

- Older patients have the right to access evidencebased treatments. Clinical studies must recruit patients who stand to benefit most from the intervention under investigation. Older patients have a high burden of cardiovascular disease, are growing significantly in number and thus may benefit significantly from novel management approaches. Future cardiovascular studies should (1) promote the inclusion of older patients, (2) aim to recruit a majority of women, (3) consider the removal of an upper age limit, (4) have accessible mechanisms of follow-up and (5) include relevant, age-sensitive outcome measures. 
to $2011 .{ }^{1}$ Over this period, the fastest increases were observed in the number over 85, which doubled from 0.7 to 1.4 million. $^{1}$ Ischaemic heart disease (IHD) remains the leading cause of death in men and women over the age of 65 years. National data demonstrate that $49 \%$ of all myocardial infarction (MI) occurs in patients aged over 70 years; $34.2 \%$ of all percutaneous coronary intervention (PCI) procedures are performed in this group. ${ }^{2}$ Thus, the number of older patients with MI, presenting to health services and requiring evidencebased treatment, will increase markedly.

Older patients presenting with acute coronary syndrome (ACS) are at higher risk of adverse outcomes; each 10-year increase in age confers a $75 \%$ increase in in-hospital mortality. ${ }^{4}$ Despite this well-documented adverse risk profile, older patients remain significantly under-represented in clinical cardiovascular studies. Indeed, 55.2\% of randomised controlled trials (RCTs) of ACS therapies reported between 1996 and 2000 did not enrol any patients over the age of 75 years; $31.9 \%$ actively excluded patients in this age group. ${ }^{5}$ The lack of data regarding the safety and efficacy of interventions in older patients and particularly those over 85 years undermines the practice of evidence-based medicine in this high-risk cohort. However, observational studies of older patients in other disciplines have shown robust recruitment rates and a willingness among this age group to actively participate in medical research. ${ }^{6}$ Improving the enrolment of older patients, as well as overcoming the unique challenges associated with the retention of these patients, is an imperative priority in clinical cardiology research.

The present study evaluates the recruitment of older patients to a prospective cohort study, quantifies the challenges faced during recruitment and identifies the factors associated with non-participation in order to provide insights and refine recruitment strategies in future clinical studies.

\section{METHODS}

\section{Study design}

The study to Improve Cardiovascular Outcomes in high-risk patieNts with ACS (ICON-1) is an observational, prospective cohort study, investigating predictors of poor outcome in patients aged $\geq 75$ years, undergoing invasive management for non-ST-elevation MI (NSTEMI) and unstable angina (UA). ICON-1 prospectively recruited patients referred to the Freeman Hospital in Newcastle upon Tyne, UK, a high-volume tertiary cardiac centre which performs $>3000$ PCI procedures annually.

All patients presenting with ACS, aged $\geq 75$ years and listed for urgent PCI in the cardiac catheterisation laboratory were screened by the study team. Study inclusion criteria were (1) age $\geq 75$ years and (2) non-ST-elevation ACS managed via an invasive approach (ie, angiography $\pm \mathrm{PCI}$ ). Exclusion criteria comprised (1) cardiac arrest, ventricular arrhythmia or cardiogenic shock at presentation or during admission; (2) moderate or severe valvular disease; (3) malignancy or other lifelimiting comorbidity, with $<1$ year predicted survival; or (4) active infection during admission. Patients with latepresentation ST-elevation MI, or stable angina, were not included. Participants provided written, informed consent prior to their inclusion in the study. Formal assessment of capacity was performed where applicable; all patients lacking the capacity to provide written, informed consent were not approached to participate. Patients were managed at the discretion of the operator. If coronary angiography suggested a non-ACS final diagnosis, the patient was also excluded. Table 1 displays the additional investigations performed, as per the ICON-1 study protocol. A 1-year follow-up clinical consultation was performed.

The ICON-1 study was approved by the appropriate Local Ethics Committee and National Research Ethics Service (NRES; 12/NE/0160) and is compliant with the principles outlined in the Declaration of Helsinki. ICON-1 is registered with the United Kingdom Clinical Research Network (UKCRN; ID 12742) and ClinicalTrials.gov (NCT01933581). Data are presented from the study recruitment period from February 2013 to December 2015.

\section{Screening protocol}

Patients fulfilling the study inclusion criteria, and without exclusion criteria, were approached on arrival to the ward. The study was explained in detail, verbally and using a comprehensive written information sheet, and the patient afforded the opportunity to ask questions. The patient was given time to consider, before the researcher returned to address any further questions and obtain formal, written, informed consent. Patients were given a minimum of 2 hours to consider participation; where possible, the patient was approached the evening prior to angiography and provided informed consent (where possible) the following morning. In patients with visual impairment, the information sheet and consent form were read in full. Patients unable to consent, for example, due to language difficulties, severe deafness, blindness or a lack of capacity, were not recruited. Some patients requested that a family member was present during the consent process, which was accommodated. Details of all patients that underwent screening, whether recruited or not were entered into an anonymised screening log.

\section{Statistical analysis}

Continuous data are expressed in the form of mean \pm SD and, where parametrically distributed, analysed using unpaired Student's t-test. Discrete variables were expressed as numbers and percentages and analysed using Pearson's $\chi^{2}$ test or Fisher's exact test if the contingency table cell count was $<5$. The Statistical Package for Social Sciences (SPSS) V.23.0 (SPSS, Chicago, Illinois, USA) was used for all analyses. 
Table 1 Baseline characteristics, stratified by eligibility and recruitment status

\begin{tabular}{|c|c|c|c|c|c|c|c|}
\hline & \multirow{2}{*}{$\begin{array}{l}\text { All patients } \\
\text { screened } \\
\text { (A) } \\
n=629\end{array}$} & \multirow{2}{*}{$\begin{array}{l}\text { Eligible } \\
\text { patients } \\
(B) \\
n=457\end{array}$} & \multirow{2}{*}{$\begin{array}{l}\text { Recruited } \\
\text { patients (C) } \\
n=300\end{array}$} & \multirow{2}{*}{$\begin{array}{l}\text { Non-recruited } \\
\text { patients (D) } \\
\mathrm{n}=157\end{array}$} & \multicolumn{3}{|c|}{$\begin{array}{l}p \text { Values for difference } \\
\text { between groups }\end{array}$} \\
\hline & & & & & A vs $B$ & B vs C & C vs D \\
\hline Female (\%) & $275(43.7)$ & $210(46.0)$ & $117(39.0)$ & $93(59.2)$ & 0.310 & $0.033^{\star}$ & $<0.001^{\star * *}$ \\
\hline Age (years) & $81.2 \pm 4.8$ & $81.1 \pm 4.7$ & $80.5 \pm 4.7$ & $82.2 \pm 4.7$ & 0.231 & 0.100 & $<0.001^{\star \star \star}$ \\
\hline \multicolumn{8}{|l|}{ Presentation } \\
\hline NSTEMI (\%) & $458(72.8)$ & $348(76.1)$ & $246(82.0)$ & 105 (66.9) & & & \\
\hline UA (\%) & $86(13.7)$ & $67(14.7)$ & $51(17.0)$ & $19(12.1)$ & $0.032^{*}$ & $<0.001^{* \star *}$ & $<0.001^{\star \star \star}$ \\
\hline Other (\%) & 85 (13.5) & $38(8.3)$ & $3(1.0)$ & $33(21.0)$ & & & \\
\hline Hypertension (\%) & $475(75.5)$ & $342(74.8)$ & $225(75.0)$ & $117(74.5)$ & 0.797 & 0.959 & 0.911 \\
\hline Diabetes (\%) & $162(25.8)$ & $112(24.5)$ & $70(23.3)$ & $42(26.8)$ & 0.640 & 0.712 & 0.420 \\
\hline \multicolumn{8}{|l|}{ Smoking status } \\
\hline Current smoker (\%) & $37(5.9)$ & $28(6.1)$ & $17(5.7)$ & $11(7.0)$ & & & \\
\hline Ex-smoker (\%) & 377 (59.9) & $251(54.9)$ & $162(54.0)$ & 89 (56.7) & 0.242 & 0.914 & 0.648 \\
\hline Never smoked (\%) & $215(34.2)$ & $178(38.9)$ & $121(40.3)$ & 57 (36.3) & & & \\
\hline Hypercholesterolaemia (\%) & $358(56.9)$ & $264(57.8)$ & $180(60.0)$ & $84(53.5)$ & 0.779 & 0.541 & 0.181 \\
\hline Family history of IHD (\%) & $160(25.4)$ & $125(27.4)$ & $97(32.3)$ & $28(17.8)$ & 0.479 & 0.141 & $<0.001^{\star * *}$ \\
\hline Renal impairment (\%) & 159 (25.3) & $107(23.4)$ & $68(22.7)$ & $39(24.8)$ & 0.481 & 0.812 & 0.602 \\
\hline Previous MI (\%) & $221(35.1)$ & $147(32.2)$ & 95 (31.7) & $52(33.1)$ & 0.308 & 0.885 & 0.651 \\
\hline Previous PCI (\%) & $138(21.9)$ & $95(20.8)$ & $61(20.3)$ & $34(21.7)$ & 0.648 & 0.880 & 0.741 \\
\hline Peripheral vascular disease (\%) & $63(10.0)$ & $42(9.2)$ & $28(9.3)$ & $14(8.9)$ & 0.649 & 0.947 & 0.883 \\
\hline Cerebrovascular disease (\%) & $80(12.7)$ & $57(12.5)$ & $44(14.7)$ & $13(8.3)$ & 0.904 & 0.489 & 0.065 \\
\hline Radial access (\%) & $549(87.3)$ & $411(89.9)$ & $268(89.3)$ & $143(91.1)$ & 0.178 & 0.790 & 0.555 \\
\hline \multicolumn{8}{|l|}{ Treatment } \\
\hline $\mathrm{PCl}(\%)$ & $456(72.5)$ & $349(76.4)$ & $251(83.7)$ & $98(62.4)$ & & & \\
\hline CABG (\%) & $17(2.7)$ & $11(2.4)$ & $8(2.7)$ & $3(1.9)$ & 0.354 & 0.310 & $<0.001^{\star \star \star}$ \\
\hline Medical management (\%) & $156(24.8)$ & $97(21.2)$ & $41(13.7)$ & $56(35.7)$ & & & \\
\hline $\begin{array}{l}\text { Number of stents in those } \\
\text { receiving } \mathrm{PCl}\end{array}$ & $1.7 \pm 1.3$ & $1.7 \pm 1.2$ & $1.8 \pm 1.1$ & $1.6 \pm 1.4$ & 0.932 & 0.534 & 0.142 \\
\hline $\begin{array}{l}\text { Continuous variables are presented } \\
{ }^{*} \text { Significant at } p<0.05 \text { level, }{ }^{* *} \text { signifi } \\
\text { CABG, coronary artery bypass surg } \\
\text { infarction; } \mathrm{PCl} \text {, percutaneous coron }\end{array}$ & $\begin{array}{l}\text { e form of } m \\
\text { at } p<0.01 \text { le } \\
H D \text {, ischae }\end{array}$ & D, and d & $\begin{array}{l}\text { te variables } \\
p<0.001 \text { le }\end{array}$ & resented in $t$ & of $n$ & tion & dial \\
\hline
\end{tabular}

This study is reported in compliance with the STrengthening the Reporting of OBservational studies in Epidemiology (STROBE) statement. ${ }^{7}$

\section{RESULTS \\ Patient characteristics}

Of the 629 patients initially screened, 457 (72.7\%) satisfied the a priori-defined eligibility criteria and were approached to participate in ICON-1. The average age of those screened was $81.2 \pm 4.8$ years (mean $\pm \mathrm{SD}) ; 43.6 \%$ were women. Of those approached, 319 (69.8\%) provided informed consent and were recruited to ICON-1. Following angiography, 18 patients were given non-ACS final diagnoses, and 1 patient withdrawn their consent. Accordingly, these patients were excluded from the present study, giving a total of $n=300$ patients recruited. The recruitment of the ICON-1 patient cohort is summarised in figure 1 . The characteristics of patients eligible for recruitment were not significantly different from the population screened. The final cohort recruited did not differ significantly from the population screened or eligible patients, with the exception of (1) recruiting fewer female patients $(39 \%$ of recruited cohort vs $46.0 \%$ of eligible patients, $\mathrm{p}=0.033$ ) and (2) mode of presentation (eg, NSTEMI comprised $82.0 \%$ of recruited cohort, cf. $76.1 \%$ of eligible patients; $\mathrm{p}<0.001$ ). Data demonstrate equivalent risk factor distributions in the screened, eligible and recruited populations, with the exception of family history of IHD $(p<0.001)$. The baseline characteristics of patients screened, as stratified by recruitment status, are shown in table 2 .

\section{Study non-recruitment}

In total, 59 eligible patients $(13.5 \%)$ were unable to provide informed consent to participate in ICON-1. Most commonly, this was a result of the patient lacking capacity to provide such informed consent $(n=45$; $76.3 \%)$, as assessed in accordance with the principles outlined in the UK Mental Capacity Act (2005). The remaining patients $(n=14 ; 23.7 \%)$ were unable to provide informed consent as a consequence of significant language difficulties, severe deafness or blindness. Those unable to provide informed consent were, on average, older than those able to provide informed consent $(83.0 \pm 4.7$ vs $81.0 \pm 4.7$ years, $\mathrm{p}=0.002)$, but there 
Figure 1 Flow diagram of patients screened for inclusion in ICON-1. ACS, acute coronary syndrome; CABG, coronary artery bypass graft; $\mathrm{PCl}$, percutaneous coronary intervention.

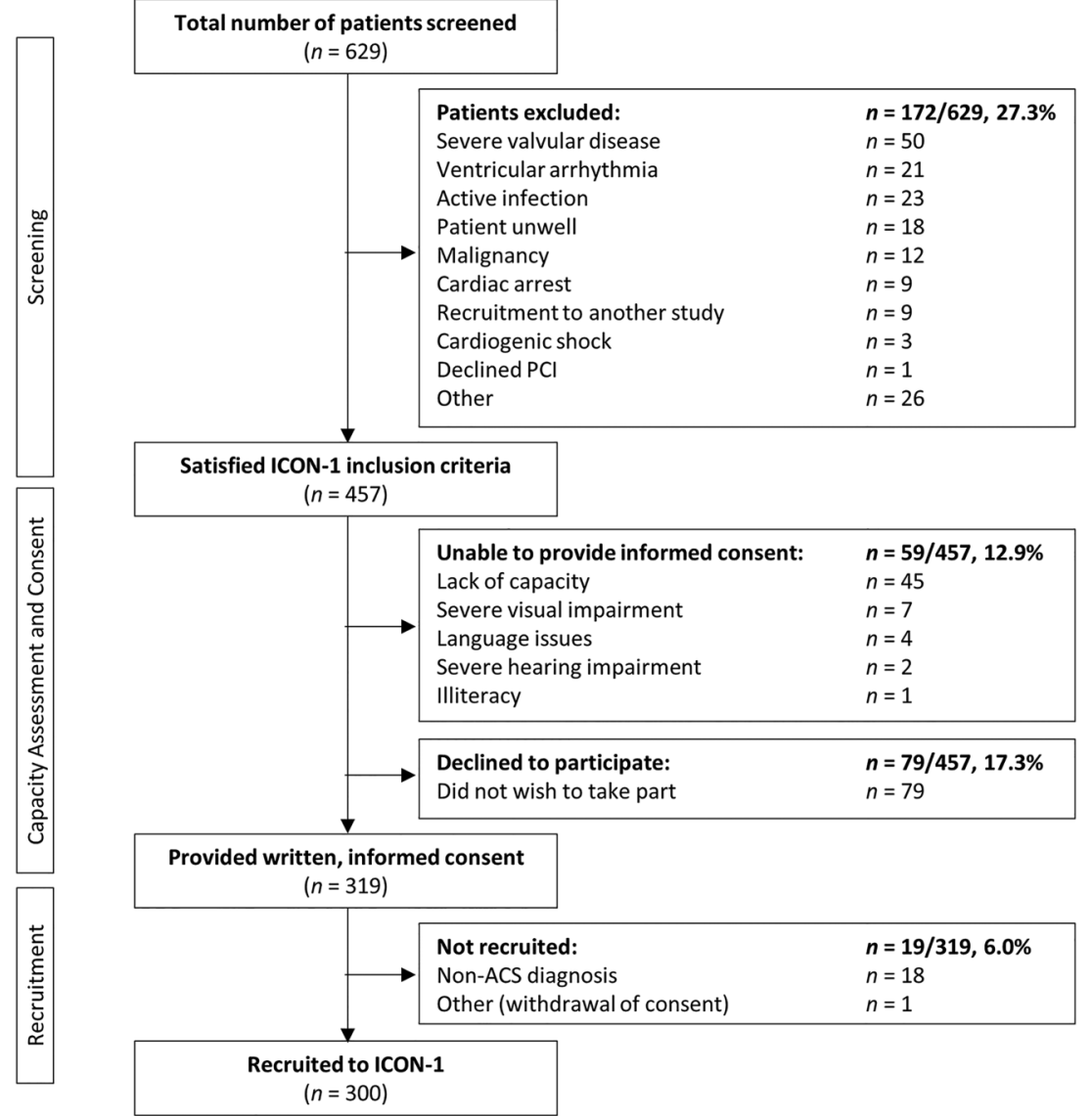

was no difference between genders in the ability to provide informed consent $(13.5 \%$ of women were unable to consent vs $12.0 \%$ of men, $\mathrm{p}=0.631)$.

Overall, 79 otherwise eligible patients (18.0\%) declined to participate in the study (table 3 ). The majority of patients that declined did not offer a specific reason for declining; $17.7 \%$ felt too anxious about the coronary angiography and PCI procedure to consider taking part in a study that entailed additional procedures, and $15.2 \%$ did not wish to consider participate in any research study. More women declined to participate in the study compared with men $(25.1 \%$ vs $10.0 \%$, $\mathrm{p}<0.001$ ), as reflected in the lower number of women recruited to the study overall. There was no significant difference in age between those that declined and consented $(81.9 \pm 4.7$ vs $81.5 \pm 4.7$ years, $\mathrm{p}=0.571)$.

\section{Patients aged 85 years and older}

In total, 143 patients aged 85 years and older were screened for inclusion; $102(71.3 \%)$ were eligible to participate. Of those eligible, $55(53.9 \%)$ were successfully enrolled in ICON-1. The oldest patient recruited was 93 years old. The greatest exclusion criterion in this subgroup was significant valvular disease; 24 patients over 85 years old were ineligible to participate due to the presence of concomitant moderate-to-severe valvular pathology. A total of 24 patients were unable to provide informed consent; 23 patients declined to participate.

\section{DISCUSSION}

Historically, the recruitment of older patients to clinical research has represented a significant challenge. In the present study, for the first time, we have demonstrated that the majority of patients satisfying the study inclusion criteria $(69.8 \%)$ were successfully recruited to participate in the ICON-1 study, with a reciprocally low rate of patients declining to participate $(18.0 \%)$. Those who declined were more likely to be women, and those unable to provide informed consent (13.5\%) were older than those who could.

Despite a recent focus on the importance of recruiting older people to cardiovascular research, the majority of RCTs and observational studies fail to recruit older patients with ACS, and a significant minority actively exclude them. This leads to a continuing paucity of data in this age group. Of the 44 RCTs in ACS reported in 2014, 10 studies $(22.7 \%$ ) had upper age limits (4 RCTs excluded patients $>75$ years, 4 excluded $>80$ years, 1 excluded $>85$ years and 1 excluded $>90$ years). The average age of participants across all RCTs was 62.0 \pm 6.8 years. Only 2 RCTs $(4.5 \%)$ specifically recruited older patients. ${ }^{89}$ Of the 70 published prospective, observational studies, $11(15.7 \%)$ had upper age limits (1 study excluded $>55$ years, 3 excluded $>75$ years, 5 excluded $>80$ years and 2 excluded $>85$ years). The average age of participants was $61.3 \pm 5.9$ years. Two observational studies $(2.9 \%)$ specifically recruited older 
Table 2 Investigations performed in the ICON-1 study

\begin{tabular}{|c|c|c|}
\hline Investigation & Performed & Time taken \\
\hline Blood tests & $\begin{array}{l}30 \mathrm{~mL} \text { blood taken in cardiac catheterisation laboratory } \\
\text { and at } 1 \text { year follow-up }\end{array}$ & As part of routine care \\
\hline $\begin{array}{l}\text { Invasive imaging: } \\
\text { V Virtual histology intravascular ultrasound } \\
\text { - Optical coherence tomography }\end{array}$ & In cardiac catheterisation laboratory & $15 \min$ \\
\hline Arterial stiffness & Day 1 post-PCl & $15 \min$ \\
\hline Endothelial function & Day 1 post-PCI & $15 \min$ \\
\hline Carotid intima media thickening & Day 1 post-PCl & $5 \mathrm{~min}$ \\
\hline Transthoracic echocardiography & Day 1 post-PCl & $10 \mathrm{~min}$ \\
\hline $\begin{array}{l}\text { Frailty assessments: } \\
\text { Fried criteria } \\
\text { Rockwood criteria }\end{array}$ & Day 1 post-PCI and at 1 year follow-up & $5 \mathrm{~min}$ \\
\hline $\begin{array}{l}\text { Quality of life questionnaire: } \\
\text { EQ-5D }\end{array}$ & Day 1 post- $\mathrm{PCl}$ and at 1 year follow-up & $15 \min$ \\
\hline $\begin{array}{l}\text { Cognitive assessment: } \\
\text { Montreal cognitive assessment }\end{array}$ & Day 1 post- $\mathrm{PCl}$ and at 1 year follow-up & $10 \mathrm{~min}$ \\
\hline
\end{tabular}

patients. ${ }^{10} 11$ A systematic review of RCTs in ACS demonstrated that the percentage of randomised trials excluding older patients appears to be falling, from $31.9 \%$ in 1996-2001 to $22.7 \%$ in $2014 .^{5}$ Indeed, although enrolment of older patients ( $\geq 75$ years) has increased in recent decades, only $10.3 \%$ of patients fell into this age category in RCTs published between 1996 and 2000. ${ }^{5}$

The recruitment rate of older patients to ICON-1 compares favourably to other observational, noncardiovascular studies in the older population, such as the Newcastle $85+$ study $(71.7 \%) .{ }^{6}$ Despite recruiting from a similar geographic area, the Newcastle 85+ study enrolled patients using a community register and did not approach patients in secondary care, undergoing invasive investigations.

Several cardiovascular studies have exclusively recruited older patients, with mixed success. The Italian Elderly ACS study recruited a population comparable to ICON-1, patients with non-ST-elevation ACS, aged $\geq 75$

Table 3 Reasons for declining to participate

\begin{tabular}{ll}
\hline Reason & $\begin{array}{l}\text { Number } \\
(\mathbf{n}=79)\end{array}$ \\
\hline No specific reason & $26(32.9 \%)$ \\
Anxiety about PCl procedure & $14(17.7 \%)$ \\
Not keen on taking part in any research & $12(15.2 \%)$ \\
Felt too unwell to consider study & $8(10.1 \%)$ \\
Concerned about distance from research & $7(8.9 \%)$ \\
venue & $5(6.3 \%)$ \\
Worried about being carer for spouse & $3(3.8 \%)$ \\
Recent bereavement & $3(3.8 \%)$ \\
Already taken part in other research & $1(1.3 \%)$ \\
Needed to talk through with absent family & \\
member & \\
\hline PCI, percutaneous coronary intervention. &
\end{tabular}

(mean 82) years. ${ }^{12}$ Patients were randomised to either receive an early invasive or conservative management strategy. Initially planning to recruit 504 patients, the trial design was amended due to a slower-than-expected recruitment rate. In total, 313 patients were recruited, resulting in limited statistical power. The investigators attributed slow recruitment to a number of factors, including difficulty in obtaining informed consent and significant comorbidity burden, making many patients ineligible for recruitment due to exclusion criteria. Recently, the After Eighty study recruited 457 patients, aged $\geq 75$ (mean 82 ) years, also evaluating conservative versus invasive management of non-ST-elevation ACS. ${ }^{13}$ This study screened 1973 patients for inclusion, but only $23 \%$ were recruited. The authors credit the low recruitment rate to logistical reasons and refusal to participate. Thus, significant lessons should be learnt from these trials, in order to better inform the design of future studies, in the older population. Specifically, further qualitative work is indicated to explore reasons for nonparticipation and to design interventions that maximise participation.

Our study is the first study to evaluate the recruitment rate in detail among older patients presenting with ACS (NSTEMI and UA) providing important insights into the recruitment of such patients in future clinical studies. In the UK, the set-up of the multicentre, the British Heart Foundation SENIOR-RITA, trial is currently underway. ${ }^{14}$ Whether the beneficial effects of revascularisation will be demonstrated in older patients ( $\geq 75$ years) with comorbidities presenting with NSTEMI is unknown and will be investigated in SENIOR-RITA. This is particularly important as this potentially frail older cohort is becoming more prevalent. SENIOR-RITA specifically aims to investigate these high-risk comorbid frail older patients who are being denied advanced cardiovascular care due to fear of complications and 
perception of futility. We will include all-comer older patients ( $\geq 75$ years) with NSTEMI, including those with comorbidities and those with cognitive impairment who normally would be denied invasive care due to underlying comorbidity and in whom there is lack of evidence currently in the management of NSTEMI.

Patients approached to participate in ICON-1 were generally enthusiastic about participating in clinical research, citing their altruistic wish to 'give something back' and improve the treatment of patients presenting in future. This contradicts previous evidence; one cardiovascular RCT in patients aged 70-82 years found that the primary reason for taking part in research was selfinterest $(52.9 \%)$, access to 'health checks' or 'peace of mind', followed by a sense of altruism (39.6\%) to 'help research' or 'help others'. ${ }^{15}$ Indeed, several patients recruited to ICON-1 mentioned the importance of as few clinic visits as possible after initial recruitment, citing a lack of transport. Seven patients cited distance from the research venue as a reason for declining to participate; previous research demonstrated inverse correlation between the distance from the older patient's residence to the research venue, and the likelihood of participation in a clinical trial. ${ }^{16}$

Several patients expressed anxiety regarding the impending PCI procedure and felt unable to consider additional procedures at that time. Care was taken by the researchers to permit the patient adequate time to assimilate the information given, often requiring multiple conversations with the patient (and their family, where possible). Older patients who agree to participate in research often take more time to make the decision than those who decline, ${ }^{17}$ and patients who feel that they have sufficient time to consider the information are more likely to consent. ${ }^{18}$ This is time-consuming for the research team and requires devoted researchers who are able to develop sufficient rapport.

Guidance on ethical research in older people has stipulated that studies should aim to recruit a majority of women, in order to reflect the gender composition of this population. ${ }^{19}$ However, women approached for participation in ICON-1 were disproportionately more likely to decline compared with men. Furthermore, the present study demonstrated an anxiety among older female patients regarding PCI, preventing them from participating in the study. In addition, five female patients declined to participate due to concerns that taking part in research would affect their ability to care for their spouse. Although a greater proportion of men than women over the age of 75 years are unpaid carers, this figure may be skewed as more women in this age group are likely to be widowed. ${ }^{1}$ Indeed, three further female patients in our cohort declined due to recent bereavement. Thus, researchers must be sensitive to such issues when approaching older and particularly female patients for participation in clinical studies.

Patients unable to provide informed consent were, on average, older than those able to provide consent. The most frequent reason for being unable to provide consent was a lack of capacity, secondary to cognitive impairment $(70 \%)$ either long-standing, or as a result of a delirium state. Around $10 \%$ of the population aged over 85 years have dementia $;^{20}$ all research involving older patients should take due consideration of mental capacity and incorporate formal capacity assessment into the process of informed consent. It is still possible to recruit patients lacking mental capacity, while protecting them from undue coercion, allowing the older patient to participate and benefit from the advances brought about by such research. In the UK, specific Research Ethics Committees consider the involvement of patients without capacity on an individual study basis. ${ }^{21}$

Given the evidence suggesting that older patients are willing to participate in clinical research, is the poor historical recruitment the fault of study investigators? In one notable study of patients with breast cancer, investigators approached $51 \%$ of patients aged $<65$ years compared to only $35 \%$ of those aged $\geq 65$ years $(p=0.006){ }^{22}$ However, age was not a predictor of the patient providing informed consent $(56 \%$ aged $<65$ years vs $50 \%$ aged $\geq 65$ years, $\mathrm{p}=0.67) .{ }^{22}$ In not offering a trial to older patients, physicians cited greater perceived therapeutic toxicity (33\%), unavailability of best-option treatment $(27 \%)$, unawareness of eligibility criteria $(21 \%)$ and incorrect suppositions of patient ineligibility $(18 \%){ }^{22}$ A further study of over 1000 patients with breast cancer demonstrated that investigators cited age as a factor in opting not to discuss a trial in $17 \%$ of patients aged $\geq 65$ years vs $3 \%$ of younger patients $(p=0.04) .{ }^{23}$ A significant change in attitudes towards involvement of older patients in research is required if we are to see substantial improvements in recruitment.

Recently, the PREDICT (increasing the PaRticipation of the ElDerly In Clinical Trials) Consortium has compiled a charter for the rights of older patients in clinical trials, aiming to narrow the gap between populations recruited to clinical trials and real-world clinical practice. ${ }^{24} 25$ The charter outlines the following: (1) older people have the right to access evidence-based treatments, (2) clinical trials should be made as practicable and safe as possible for older people, (3) outcome measures should be relevant for older people, (4) the values of older people participating in clinical trials should be respected and (5) the promotion of the inclusion of older people in clinical trials to prevent discrimination. Guidelines published by the Geriatric Working Party of the European Forum for Good Clinical Practice suggest that research should (1) actively recruit patients aged over 75 years with no upper age limit, (2) recruit a majority of women and (3) must justify exclusion comorbidities in order to accurately reflect the population studied. ${ }^{19}$

The extent to which the results of this study can be generalised to all research in older people is limited by the population studied in ICON-1. The study was an observational cohort study rather than a RCT; the 
strategies employed to yield that high recruitment rate observed may not be applicable to the latter. Importantly, the population screened for recruitment for ICON-1 had been selected; patients were only referred for PCI from their district general hospitals if a cardiologist had deemed them sufficiently fit. ICON-1 may therefore have recruited from a pool of patients more robust and/or motivated than is representative of the entire population of patients with non-ST-elevation ACS and aged over 75 years. However, given the wide case mix and large sample size, this cohort is representative of older patients receiving contemporary invasive treatment for the management of ACS in the UK.

\section{CONCLUSION}

The recruitment rate of older patients to studies in ACS remains low even in the contemporary era, resulting in a paucity of data in this high-risk cohort. However, the contribution of older patients must not be ignored, particularly in the setting of an ever-ageing population, in whom cardiovascular disease burden is high. The recruitment of older patients to the present study was robust, comparing favourably to previous longitudinal studies within this age group. Although enrolling older people to research remains challenging and requires significant adaptation from the inception of study design, this cohort is generally enthusiastic to participate. By taking the time to build rapport with the older patient, identifying issues with consent, involving relatives in the decision-making process and minimising the burden of the study on the participant, researchers can ensure that this valuable cohort of patients can contribute to our understanding and management of cardiovascular disease.

Twitter Follow Jonathan Batty at @JonnyBatty

Acknowledgements The authors acknowledge Dr J Ahmed, Dr A Bagnall, Dr R Das, Dr R Edwards, Dr M Egred, Dr I Purcell, Professor I Spyridopoulos and Professor A Zaman of Freeman Hospital, Newcastle upon Tyne for their help facilitating patient recruitment and with data collection during ICON-1. They also acknowledge Professor Stuart Parker, Newcastle University, for his comments on the manuscript.

Contributors HS and JAB wrote the manuscript. VK conceived the study and provided detailed critical review of the manuscript. WQ provided statistical support.

Funding The research is supported by the National Institute for Health Research (NIHR) Newcastle Biomedical Research Centre (BRC) based at Newcastle-upon-Tyne Hospitals NHS Foundation Trust and Newcastle University.

Disclaimer The views expressed are those of the authors and not necessarily those of the NHS, the NIHR or the Department of Health.

Competing interests None declared.

Patient consent Consent was obtained from patients.

Ethics approval REC South of Tyne Committee NRES; 12/NE/0160.

Provenance and peer review Not commissioned; externally peer reviewed.

Open Access This is an Open Access article distributed in accordance with the Creative Commons Attribution Non Commercial (CC BY-NC 4.0) license, which permits others to distribute, remix, adapt, build upon this work noncommercially, and license their derivative works on different terms, provided the original work is properly cited and the use is non-commercial. See: http:// creativecommons.org/licenses/by-nc/4.0/

\section{REFERENCES}

1. Office for National Statistics. 2011 Census: population and household estimates for England and Wales. London, UK: Office for National Statistics, 2012.

2. Myocardial Ischaemia National Audit Project. UK Myocardial Ischaemia National Audit Project (MINAP) Annual Public Report (2011-12). London, UK, 2012.

3. British Cardiovascular Intervention Society. National Audit of Percutaneous Coronary Interventional Procedures: Annual Public Report (January 2012-December 2012). London, UK, 2014.

4. Avezum A, Makdisse M, Spencer F, et al. Impact of age on management and outcome of acute coronary syndrome: observations from the Global Registry of Acute Coronary Events (GRACE). Am Heart J 2005;149:67-73.

5. Lee PY, Alexander KP, Hammill BG, et al. Representation of elderly persons and women in published randomized trials of acute coronary syndromes. JAMA 2001;286:708-13.

6. Davies K, Collerton JC, Jagger C, et al. Engaging the oldest old in research: lessons from the Newcastle $85+$ study. BMC Geriatr 2010;10:64.

7. von Elm E, Altman DG, Egger $\mathrm{M}$, et al. The Strengthening the Reporting of Observational Studies in Epidemiology (STROBE) statement: guidelines for reporting observational studies. Epidemiology 2007;18:800-4.

8. de Belder A, de la Torre Hernandez JM, Lopez-Palop R, et al. A prospective randomized trial of everolimus-eluting stents versus bare-metal stents in octogenarians: the XIMA Trial (Xience or Vision Stents for the Management of Angina in the Elderly). J Am Coll Cardiol 2014;63:1371-5.

9. Galasso G, De Servi S, Savonitto S, et al. Effect of an invasive strategy on outcome in patients $\geq 75$ years of age with non-ST-elevation acute coronary syndrome. Am J Cardiol 2015;115:576-80.

10. Liu $Y$, Gao L, Xue $Q$, et al. Impact of renal dysfunction on long-term outcomes of elderly patients with acute coronary syndrome: a longitudinal, prospective observational study. BMC Nephrol 2014;15:78.

11. Showkathali R, Boston-Griffiths E, Parker M, et al. Should primary percutaneous coronary intervention be the routine reperfusion strategy in octogenarians presenting with ST elevation myocardial infarction? J Cardiovasc Med (Hagerstown) 2014;15:53-9.

12. Savonitto $\mathrm{S}$, Cavallini C, Petronio AS, et al. Early aggressive versus initially conservative treatment in elderly patients with non-ST-segment elevation acute coronary syndrome: a randomized controlled trial. JACC Cardiovasc Interv 2012;5:906-16.

13. Tegn $\mathrm{N}$, Abdelnoor $\mathrm{M}$, Aaberge $\mathrm{L}$, et al. Invasive versus conservative strategy in patients aged 80 years or older with non-ST-elevation myocardial infarction or unstable angina pectoris (After Eighty Study): an open-label randomised controlled trial. Lancet 2016;387:1057-65.

14. Sinclair $\mathrm{H}$, Kunadian V. Coronary revascularisation in older patients with non-ST elevation acute coronary syndromes. Heart 2016;102:416-24.

15. Tolmie EP, Mungall MM, Louden G, et al. Understanding why older people participate in clinical trials: the experience of the Scottish PROSPER participants. Age Ageing 2004;33:374-8.

16. Ory MG, Lipman PD, Karlen PL, et al. Recruitment of older participants in frailty/injury prevention studies. Prev Sci 2002;3:1-22.

17. Duffy LM, Wyble SJ, Wilson $B$, et al. Obtaining geriatric patient consent. J Gerontol Nurs 1989;15:21-4.

18. DeLuca SA, Korcuska LA, Oberstar BH, et al. Are we promoting true informed consent in cardiovascular clinical trials? J Cardiovasc Nurs 1995;9:54-61.

19. Diener L, Hugonot-Diener L, Alvino S, et al., European Forum for Good Clinical Practice Geriatric Medicine Working Party. Guidance synthesis. Medical research for and with older people in Europe: proposed ethical guidance for good clinical practice: ethical considerations. J Nutr Health Aging 2013;17:625-7.

20. Collerton J, Davies K, Jagger $\mathrm{C}$, et al. Health and disease in 85-year-olds: baseline findings from the Newcastle 85+ cohort study. BMJ 2009;339:b4904.

21. McMurdo ME, Roberts $\mathrm{H}$, Parker S, et al. Improving recruitment of older people to research through good practice. Age Ageing 2011;40:659-65. 
22. Kemeny MM, Peterson BL, Kornblith AB, et al. Barriers to clinical trial participation by older women with breast cancer. J Clin Oncol 2003;21:2268-75.

23. Javid SH, Unger JM, Gralow JR, et al. A prospective analysis of the influence of older age on physician and patient decision-making when considering enrollment in breast cancer clinical trials (SWOG S0316). Oncologist 2012;17:1180-90.
24. Crome P, Cherubini A, Oristrell J. The PREDICT (increasing the participation of the elderly in clinical trials) study: the charter and beyond. Expert Rev Clin Pharmacol 2014;7: 457-68.

25. Hertogh CM. Development of a charter for older people in clinical trials: PREDICT. Tijdschr Gerontol Geriatr 2009;40: 180-3. 